\title{
Fabrication of novel poly ( $m$-phenylene isophthalamide) hollow fiber nanofiltration membrane for effective removal of trace amount perfluorooctane sulfonate from water
}

\author{
Tao Wang ${ }^{\mathrm{a}}$, Changwei Zhao ${ }^{\mathrm{a}, *}$, Pei Li ${ }^{\mathrm{b}}$, Ye $\mathrm{Li}^{\mathrm{c}}$, Jun Wang ${ }^{\mathrm{a}}$ \\ a Research Center for Eco-Environmental Sciences, Chinese Academy of Sciences, Beijing 100085, China \\ ${ }^{\mathrm{b}}$ College of Materials Science and Engineering, Beijing University of Chemical Technology, No.15 Beisanhuandong Road, Chaoyang District, \\ Beijing 100029, China \\ ${ }^{\mathrm{c}}$ Xiaohongmen Wastewater Treatment Plant, Beijing Drainage Group Co. Ltd., Beijing 100176, China
}

\section{A R T I C L E I N F O}

Article history:

Received 18 August 2014

Received in revised form

27 November 2014

Accepted 23 December 2014

Available online 3 January 2015

Keywords:

Nanofiltration

Hollow fiber membrane

PFOS removal

\begin{abstract}
A B S T R A C T
This study investigated the separation performance of a hollow fiber nanofiltration membrane, which was fabricated from poly ( $m$-phenylene isophthalamide) (PMIA) using a dry-jet wet spinning technology, for sustainable water recovery from water containing trace amount of perfluorooctane sulfonate (PFOS) that was a persistent organic pollutant commonly existed in water. SEM spectra indicated that the cross section of the hollow fiber membrane had an asymmetrical structure that consisted of a dense outer surface acting as a selectively layer, a spongy-like transition layer, and finger-like microvoids close to the inner surface. The average pore size and molecular weight cut-off, which were estimated using the solute rejection method, were $0.404 \mathrm{~nm}$ and $904 \mathrm{Da}$, respectively. The PFOS rejection experiments were carried out at the trans-membrane pressures ranging from $4 \times 10^{5} \mathrm{~Pa}$ to $1.0 \times 10^{6} \mathrm{~Pa}$ and PFOS concentrations from $50 \mu \mathrm{g} / \mathrm{L}$ to $500 \mu \mathrm{g} / \mathrm{L}$. In all cases, the PFOS rejections were found to be increased as the PFOS concentration increased. The impact of the $\mathrm{pH}$ value and $\mathrm{Ca}^{2+}$ concentration of the feed solution on the PFOS rejections was studied in detail. The PFOS rejections improved from $91.17 \%$ to $97.49 \%$ with an increase in $\mathrm{pH}$ from 3.2 to 9.5 at $4 \times 10^{5} \mathrm{~Pa}$. An increase of $\mathrm{Ca}^{2+}$ concentration from $0.1 \mathrm{mM}$ to $2 \mathrm{mM}$ enhanced PFOS rejection from $97.10 \%$ to $99.40 \%$ at a trans-membrane pressure of $4 \times 10^{5} \mathrm{~Pa}$. The sorption/desorption experiments indicated that the amount of PFOS adsorbed on the membrane surface was five times higher in the presence of $\mathrm{Ca}^{2+}(2 \mathrm{mM})$. AFM experiments also demonstrated that the membrane surface was rough with the addition of $\mathrm{Ca}^{2+}$. Hence, the presence of $\mathrm{Ca}^{2+}$ enhanced the PFOS adsorption in the membrane surface and caused more pore blockage of the membrane. As such, the declination in the water flux and augmentation in the PFOS rejection were observed.
\end{abstract}

(c) 2014 Elsevier B.V. All rights reserved.

\section{Introduction}

Perfluorooctane sulfonate (PFOS), a typical perfluorinated compound, is a fully fluorinated eight-carbon alkane with a sulfonate group at one end [1]. PFOS is widely used in the textile and chemical industries, coating materials, fire retardants, drug packaging materials, and surfactants owing to its excellent thermal and chemical stability, and non-hydrophilic and non-lipophilic properties [2-5]. Although PFOS plays an important role in the developing industry, its environmental persistence and bioaccumulation may be potentially hazardous [6]. PFOS and its derivatives have attracted global concerns owing to their harmful effects on the environment and humans. In

\footnotetext{
* Corresponding author. Tel./fax: +8610 62849198.

E-mail address: zhaocw@rcees.ac.cn (C. Zhao).
}

2009, PFOS was categorized as one of the persistent organic pollutants (POPs) [7]. To date, PFOS has been detected in various water supplies, especially surface water, ground water, and tap water for drinking purposes worldwide. Evidently, the PFOS contamination has posed a threat to the security of drinking water for humans in some areas $[8,9]$. Although United States and some European countries have proposed regulations to limit the use of PFOS, it is still being used in many industrial applications due to the lack of available immediate alternatives. Therefore, development of cost-effective water treatment technologies to remove PFOS has drawn increasing attentions.

PFOS is difficult to decompose under traditional conditions including oxidation, reduction, and biological degradation [10,11]. Recent studies show that some methods, such as sonochemical decomposition [12], adsorption using activated carbon or anion-exchange resins $[13,14]$, and UV-mediated photodegradation [15], can remove PFOS from aqueous solution. However, these technologies are mostly for 
wastewater treatment, and require long reaction time, high energy consumption, as well as complex and specific operating conditions. In contrast, membrane technologies, especially reverse osmosis (RO) and nanofiltration (NF), are recognized as an effective method to remove organic pollutants from water. Commercial RO and flat sheet NF membranes have shown great potential to remove PFOS from wastewater and drinking water. Tang et al. demonstrated the feasibility of using commercial RO membranes to remove PFOS from semiconductor wastewater. The experimental result showed that the RO membranes rejected $99 \%$ or more of the PFOS over a wide range of PFOS concentrations $(0.5-1500 \mathrm{mg} / \mathrm{L})$ in the feed solutions [16]. They also studied the separation performance of a water solutions containing $10 \mathrm{ppm}$ PFOS using three commercial NF flat-sheet membranes (DK, NF90 and NF270). The result showed that the rejection efficiencies for NF membranes ranged from 90\% to 99\%. [5] Zhao et al. studied the effect of calcium ions on PFOS rejections using a commercial flatsheet NF270 membrane and reported that the PFOS rejection could be enhanced from $94.0 \%$ to $99.3 \%$ with an increase of the calcium ion concentration from 0 to $2 \mathrm{mmol} / \mathrm{L}$ [17]. However, to our best knowledge, all the researches on PFOS removal are based on either commercial flat-sheet RO membranes or commercial flat-sheet NF membranes. Hollow fiber NF membranes have not been explored in this application to date. It is worth stressing that most of commercial NF membranes are thin-film composite (TFC) membranes [18], such as NF series made by Filmtec Corporation, ESNA series by Hydranautics Company, Desal series by GE Osmonics Company, NTR series by Nitto Denko Company, ATF series by Advanced membrane Technology Inc., UTC series by Toray Industries, etc., and the current dominant commercial NF membranes are generally fabricated by interfacial polymerization (IP), chemical modification or coating. Although these techniques have been widely applied in industry, their fabrication processes are sophisticated and need a long production cycle. In addition, most above-mentioned NF membrane modules are still constructed into flat-sheet, spiral-wound or tubular configurations $[19,20]$. In contrast, NF membrane modules in the hollow fiber configuration have some intrinsic advantages including: (1) the better packing destiny; (2) the lager membrane surface area per unit module volume; (3) the self-mechanical support capability; (4) no demand of feed and permeate spacers; and (5) cost-effective large-scale production and operation [21,22]. Hence, developing hollow fiber NF membranes gives an alternative (maybe more suitable) solution for PFOS water treatment. To our best knowledge, materials for fabricating NF hollow fiber membrane are mainly limited to CA, PPESK, PES, etc. [21,23-29]. The development of poly( $m$-phenylene isophthalamide) (PMIA) NF hollow fiber membrane has not been reported before. PMIA has outstanding thermal resistivity $\left(T_{\mathrm{g}}=270{ }^{\circ} \mathrm{C}\right)$ and great chemical stability that makes it an ideal membrane material $[30,31]$. In addition, there is an urgent need to develop soluteselective, efficient, chemical-stable and low-priced NF membranes in hollow fiber form using adopting new outstanding materials and simple spinning technologies. Thus, this work explored the feasibility of using PMIA to fabricate hollow fiber NF membrane for treating PFOS wastewater.

Above all, there is an urgent need to develop solute-selective, more efficient, chemical-stable and low-priced NF membranes in hollow fiber form through adopting new outstanding materials and simple spinning technologies. In this study, poly( $m$-phenylene isophthalamide) (PMIA) NF hollow fiber membranes have been prepared by a dry-jet wet spinning technology. And the resulted hollow fiber membranes were investigated for the removal of PFOS from aqueous solution. The separation performance and morphologies of the PMIA membranes are characterized, and the effects of PFOS concentration, solution $\mathrm{pH}$, and ionic strength on the water flux and PFOS rejection are investigated.

\section{Materials and methods}

\subsection{Materials}

Potassium perfluorooctane sulfonate (PFOS, $\geq 99 \%$, molecular weight $=538 \mathrm{Da}$, molecule size $=1.088 \mathrm{~nm}$ ) was purchased from AccuStandard, Inc. (New Haven, USA) and its chemical and molecular structures are shown in Fig. 1. Poly ( $m$-phenylene isophthalamide) (PMIA, molecular weight $=140,000 \mathrm{Da})$ was obtained from DuPont (USA) and its chemical structure is shown in Fig. 2. HPLC-grade acetonitrile and methanol were acquired from Fisher Scientific (China). Sodium chloride $(\mathrm{NaCl})$, sodium sulfate $\left(\mathrm{Na}_{2} \mathrm{SO}_{4}\right)$, magnesium chloride $\left(\mathrm{MgCl}_{2}\right)$, magnesium sulfate $\left(\mathrm{MgSO}_{4}\right)$, and calcium chloride $\left(\mathrm{CaCl}_{2}\right)$ (analytical grade, >99\%) were bought from Sinopharm Chemical Reagent Co., Ltd. (China). Calcium chloride, humic acid sodium salt, sodium hydroxide, and hydrochloric acid (analytical grade, > 99\%) were supplied by Sigma-Aldrich (USA). N,N-dimethylacetamide (DMAc, > 98\%) was employed as PMIA solvent and purchased from Shanghai Jingwei Chemical Co., Ltd. (China). PVP K15 (Average MW $=10,000 \mathrm{Da}$ ) was obtained from Tokyo Chemical Industry Co., Ltd (Japan). Lithium chloride ( $\mathrm{LiCl},>95 \%$ ) and acetone ( $>99.5 \%$ ) were supplied by Tianjin Guangfu Research Institute of Fine Chemical Engineering (China). Glucose, saccharose, raffinose, and $\alpha$-cyclodextrin were purchased from Sigma-Aldrich (USA). Molecular weights, diffusivity properties, and Stokes radii of the neutral solutes are listed in Table 1 [32]. High-purity Milli-Q water with an electrical resistivity of $18.2 \mathrm{M} \Omega \mathrm{cm}$ was used in all experiments.

\subsection{Preparation of PMIA NF hollow fiber membrane and membrane module}

A polymer dope solution of PMIA/DMAc/LiCl/acetone/PVP K15 (20/66/4.5/8/1.5 wt\%) was prepared in a reaction vessel. The mixture was continuously stirred until a homogeneous polymer solution was obtained. After that, the dope was degassed for $12 \mathrm{~h}$. A dry-jet wet spinning method was used to prepare the PMIA hollow fiber NF membrane. The dope solution and bore fluid were

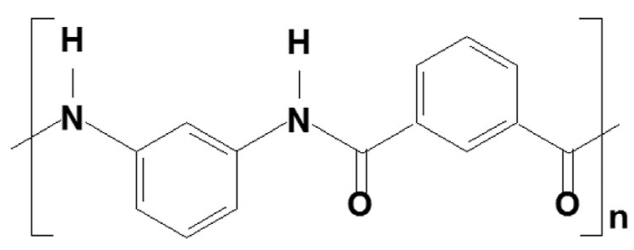

Fig. 2. The chemical structure of PMIA.

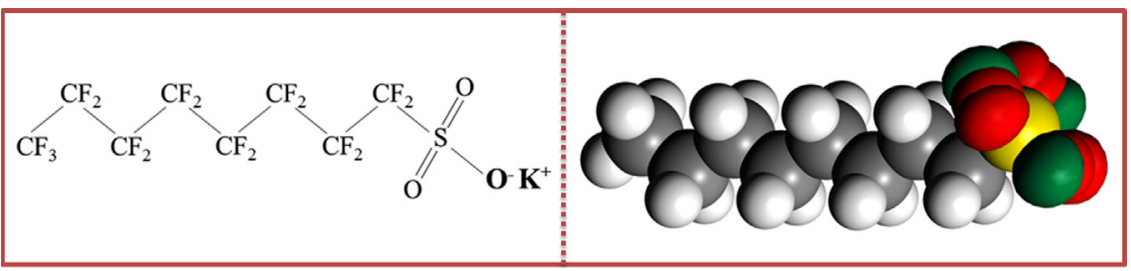

Fig. 1. The chemical structure and molecular structure of PFOS. 
co-extruded through a spinneret to form a hollow fiber. The detailed spinning parameters are listed in Table 2. The hollow fibers were soaked in a circulating water bath for $72 \mathrm{~h}$ to leach out the residual solvent. After that, the hollow fiber membrane was transferred to a $50 \mathrm{wt} \%$ glycerol aqueous solution for $48 \mathrm{~h}$ and then air-dried at room temperature.

Eight filament modules with an effective membrane length of $22 \mathrm{~cm}$ were fabricated. Specifically, 8 PMIA hollow fiber membranes were assembled into a nylon tube. Each module was sealed by epoxy and then immersed in deionized water for one day to remove glycerol before use.

\subsection{Characterization of the membrane morphology}

The structure and morphology of the NF hollow fiber membrane were monitored on a HITACHI S-3000N scanning electron microscope (SEM, Hitachi Ltd., Japan). Before observation, the membrane samples (surface and cross-section) that were randomly selected were frozen in liquid nitrogen, fractured, and sputtered with platinum using a HITACHI E-1010 ion sputtering coater.

\subsection{Membrane performance tests}

Filtration experiments were conducted using a cross-flow inhouse laboratory-scale membrane test unit (shown in Fig. 3). The

\section{Table 1}

Diffusivities and Stokes radii of neutral solutes in aqueous solutions (at $25^{\circ} \mathrm{C}$ ).

\begin{tabular}{llll}
\hline Solute & MW $(\mathrm{g} / \mathrm{mol})$ & $D_{\mathrm{s}}\left(\times 10^{-9} \mathrm{~m}^{2} \mathrm{~s}^{-1}\right)$ & $r_{\mathrm{s}}(\mathrm{nm})$ \\
\hline Glucose & 180 & 0.67 & 0.365 \\
Saccharose & 342 & 0.52 & 0.471 \\
Raffinose & 504 & 0.42 & 0.584 \\
$\alpha$-Cyclodextrin & 972 & 0.35 & 0.701 \\
\hline
\end{tabular}

Table 2

The spinning conditions of PMIA hollow fiber nanofiltration membrane.

\begin{tabular}{ll}
\hline Spinning parameters & Value \\
\hline Dope solution temperature $\left({ }^{\circ} \mathrm{C}\right)$ & 50 \\
Spinneret dimension OD/ID $(\mathrm{mm})$ & $1.40 / 0.70$ \\
Bore fluid/external coagulant & Tap water $25 \pm 1^{\circ} \mathrm{C}$ \\
Dope flow rate $(\mathrm{mL} / \mathrm{min})$ & 6.0 \\
Bore fluid flow rate $(\mathrm{mL} / \mathrm{min})$ & 3.0 \\
Air gap $(\mathrm{cm})$ & 25 \\
Take-up speed & Free fall \\
Room relative humidity $(\%)$ & $25 \pm 3$ \\
\hline
\end{tabular}

hollow fiber membrane modules were outside-in modes. The flow rate of the feed solutions was fixed to be $1.50 \mathrm{~L} \mathrm{~min}^{-1}$ to minimize the effect of concentration polarization. Before permeation test, each hollow fiber module was pre-pressurized under a pressure of $10 \times 10^{5} \mathrm{~Pa}$ in order to ensure a stable flux. Subsequently, the membranes were subjected to the solute separation experiments whereby different solutions, containing inorganic salts, neutral organic solutes, and PFOS were passed through the membrane shell side. The water flux, $F\left(\mathrm{~L} / \mathrm{m}^{2} \mathrm{~h}\right)$, is determined as follows:

$F=\frac{J}{S t}$

where $J(\mathrm{~L})$ is the water permeation volume; $S\left(\mathrm{~m}^{2}\right)$ is the membrane effective filtration area; and $t(h)$ is the operation time.

The solute rejection, $R$, is calculated as follows:

$R=\left(1-\frac{C_{\mathrm{p}}}{C_{\mathrm{o}}}\right) \times 100 \%$

where $C_{\mathrm{p}}(\mathrm{g} / \mathrm{L})$ and $C_{\mathrm{o}}(\mathrm{g} / \mathrm{L})$ are the solute concentrations in the permeate and feed solutions, respectively.

The experimental design and separation procedure are described below:

(1) Determination of the salt rejections: Different inorganic salt solutions were prepared by dissolving $\mathrm{NaCl}, \mathrm{Na}_{2} \mathrm{SO}_{4}, \mathrm{MgCl}_{2}$, and $\mathrm{MgSO}_{4}$ in deionized water at a concentration of $\sim 3.4 \mathrm{mM}$. The temperature and flow rate of the feed solution were maintained at $25 \pm 1{ }^{\circ} \mathrm{C}$ and $0.32 \mathrm{~m} / \mathrm{s}$, respectively. The feed solution was circulated for $1 \mathrm{~h}$ until the entire system reached steady state. Then, the feed and permeate solutions at different pressures were sampled to measure the salt concentrations. The salt concentrations were determined using an electrical conductivity meter (DDSJ-308A, Shanghai Leici Instrument Works, China).

(2) Determination of the neutral solute rejections: The feed solutions were prepared by dissolving four neutral solutes in deionized water at a concentration of $100 \mathrm{mg} / \mathrm{L}$. The feed temperature and cross-flow rate were the same as those introduced in step (1). The trans-membrane pressure was maintained at $7 \times 10^{5} \mathrm{~Pa}$. The neutral solute separation data were used to calculate the molecular weight cut-off (MWCO), mean pore size, and pore size distribution of the membrane. The concentration of the neutral solutes in the feed and permeate solutions was determined by measuring the total organic carbon (TOC) content using a TOC analyzer (Liquid TOC, Elementar, Germany).

(3) Determination of the PFOS rejections: The PFOS solutions were prepared by dissolving PFOS in deionized water. The experimental procedure was the same as steps (1) and (2). $\mathrm{HCl}$

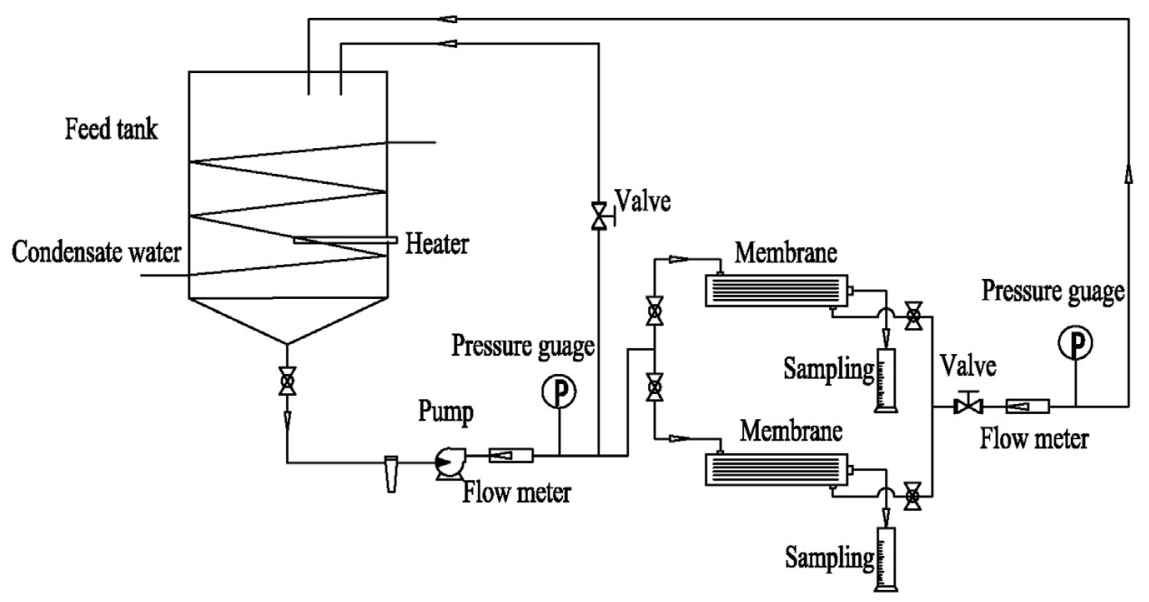

Fig. 3. Schematic diagram of the filtration unit. 
$(0.1 \mathrm{M})$ and $\mathrm{NaOH}(0.1 \mathrm{M})$ were used to adjust the $\mathrm{pH}$ of the feed solution. The concentration of PFOS in the feed and permeate solutions was determined using an ultra-performance liquid chromatography-tandem mass spectrometer (LC-MS/MS, Waters ACQUITY UPLC/Quattro Premier XE MS/MS) (Waters Corporation, USA). A C18 column $\left(2.1 \times 150 \mathrm{~mm}^{2}\right)$ obtained from Waters Corporation (USA) was used and a mixture of acetonitrile/ ammonium acetate $(70 / 30, v / v)$ was used as the mobile phase at a flow rate of $0.2 \mathrm{~mL} / \mathrm{min}$. The sample injection volume was $10 \mu \mathrm{L}$. The selected-ion monitoring (SIM) model was used to quantify the analytes $(m / z=499.05)$. A prominent peak was observed at $1.8 \mathrm{~min}$, and the detection limit for PFOS was $0.1 \mu \mathrm{g} / \mathrm{L}$. The PFOS rejection was estimated using Eq. (2) with the PFOS concentrations in the feed and permeate sides.

\subsection{Characterization of the membrane mean effective pore size and pore size distribution}

The mean effective pore size and pore size distribution of the PMIA NF hollow fiber membrane were determined using the solute transport method, as reported by Michaels and Singh $[33,34]$. The solute rejection is expressed as a log-normal probability function of solute size as follows:

$R_{\mathrm{T}}=1-\frac{C_{\mathrm{p}}}{C_{\mathrm{f}}}=\frac{1}{\sqrt{2 \pi}} \int_{-\infty}^{y} e^{-\left(u^{2} / 2\right)} \mathrm{d} u$

where $y=\left(\ln r_{\mathrm{s}}-\ln \mu_{\mathrm{s}}\right) / \ln \sigma_{\mathrm{g}}, R_{\mathrm{T}}$ is the solute rejection; $C_{\mathrm{p}}$ and $C_{\mathrm{f}}$ are the neutral concentrations of the permeate and feed solutions, respectively ; $r_{\mathrm{s}}$ is the solute radius; $\mu_{\mathrm{s}}$ is the geometric mean radius of the solute at $R_{\mathrm{T}}=50 \%$; and $\sigma_{\mathrm{g}}$ is the geometric standard deviation of $\mu_{\mathrm{s}}$ (defined as the ratio of $r_{\mathrm{s}}$ at $R_{\mathrm{T}}=84.13 \%$ and $R_{\mathrm{T}}=50 \%$ ). The cumulative pore size distribution was calculated using Eq. (3).

In the filtration experiments, by ignoring the influence of steric effects and hydrodynamic interactions between the solute and pores on solute rejection, the mean effective pore radius $\mu_{\mathrm{p}}$ and geometric standard deviation $\sigma_{\mathrm{p}}$ can be assumed to be the same as $\mu_{\mathrm{s}}$ and $\sigma_{\mathrm{g}}$, respectively. The pore size distribution of the membrane can be expressed as the following probability density function where $d_{\mathrm{p}}$ is the effective pore radius:

$\frac{d R\left(d_{\mathrm{p}}\right)}{d d_{\mathrm{p}}}=\frac{1}{d_{\mathrm{p}} 1 n \sigma_{\mathrm{p}} \sqrt{2 \pi}} \exp \left[-\frac{\left(1 n d_{\mathrm{p}}-1 n \mu_{\mathrm{p}}\right)^{2}}{2\left(1 n \sigma_{\mathrm{p}}\right)^{2}}\right]$

In this study, different solutions containing glucose, saccharose, raffinose, and $\alpha$-cyclodextrin were used to assess the solute rejection. The relationship between the Stokes radius, $r_{\mathrm{s}}(\mathrm{nm})$, and molecular weight, MW ( $\mathrm{g} / \mathrm{mol})$, of the neutral solute can be described as follows [35]:

$\log r_{s}=-1.32+0.40 \log \mathrm{MW}$

\subsection{Characterization of the membrane zeta potential}

The zeta potential of the PMIA NF hollow fiber membrane was determined at room temperature by streaming potential measurements. The $\mathrm{pH}$ values of the solution were adjusted between 3 and 9 by the addition of $0.1 \mathrm{M} \mathrm{NaOH}$ and $0.1 \mathrm{M} \mathrm{HCl}$ solutions, respectively.

\subsection{PFOS desorption studies}

After the batch experiments involving the investigation of the effect of PFOS concentration and ionic strength on membrane performance, the PFOS originally adsorbed on the membranes were desorbed in $50 \%$ (by volume) methanol aqueous solution using a thermostatic shaker at $150 \mathrm{rpm}$ and $25{ }^{\circ} \mathrm{C}$ for $24 \mathrm{~h}$. Then, the concentrations of PFOS were determined using LC-MS/MS. The desorbed amount of PFOS was estimated according to the concentration of PFOS per unit of membrane area.

\subsection{Membrane surface analysis}

All AFM measurements were performed using a Multimode SPM equiped with a J-type piezoelectric scanner and a Nanoscope III a controller ( Digital Instruments, USA ). The membranne surface images were obtained with a scan size of $5 \mu \mathrm{m} \times 5 \mu \mathrm{m}$. Roughness values were estimated from topgraphy scans using the Nanoscope control software (Version 7.30).

\section{Results and discussion}

\subsection{Morphology of PMIA NF hollow fiber membrane}

Fig. 4 illustrates the structure of the NF hollow fiber membrane that features a typical asymmetric structure comprising an outerselective skin, finger-like macrovoids, a spongy-like transition layer, and cellular-like macrovoids. During the dry-jet wet spinning process, acetone, as one volatile non-solvent additive, rapidly vaporizes to the air before the nascent hollow fiber enters the coagulant bath. It results in a more concentrated polymer solution in the outer surface than in the inner surface and bulk part of the hollow fiber. And this instigates the formation of a denser outer surface of the hollow fiber membrane that acts as the selective layer. The finger-like and cellular-like macrovoids are observed close to both the outer and inner surfaces of the hollow fiber because of the rapid liquid-liquid demixing process [36], whereas the spongy-like structure forms in the middle of the hollow fiber membrane because of the delayed phase separation. Rapid liquid-liquid demixing happens when the membrane is formed immediately after immersion into the non-solvent bath (water). Generally, when liquid-liquid demixing occurs rapidly, membranes with a relatively porous top layer, finger like cavities and cellular-like macrovoids near to the outer and inner surfaces are obtained [37]. However, in this study, the as-spun fiber firstly goes through the air gap, the volatile acetone evaporates rapidly from the outer film interface. Thus the liquid-liquid demixing process takes place after a finite period of time. Membranes with a relatively dense top layer are obtained, and the finger-like structure close to the outer surface becomes smaller and narrower [38,39]. On the contrary, the liquid-liquid demixing process that occurred at the inner surface is relatively faster than that happened near to the outer surface. That is due to that the dope solution and bore fluid (water) are co-extruded through the spinneret, and the diffusion exchange between the solvent and non-solvent is instantaneous that results in a highly unstable dope solution so that a rapid demixing process occurs. Such condition favors the formation of cellular-like macrovoid structures [40]. In the transition layer, located in the middle of the membrane, spongy-like structure is formed due to the delayed phase transition process. Two factors may lead to this result: first, the diffusion front in the transition layer moves far away from the dope solution-coagulant interface; and second, the diffusion barrier formed by the rapid liquid-liquid demixing near the outer and inner surface hinders the mutual diffusion speed between the solvent and non-solvent gel in the middle of the membrane. In this situation, it takes more induction time for non-solvent diffusing into the dope solution to form nuclei; thus the growth of the macrovoids is impossible and only a spongelike structure forms [41]. In addition, this type of structure affords high stability and good separation performance of the hollow fiber membrane under high pressure operation. Moreover, the uniform, dense, and smooth outer surface is responsible for the excellent antifouling property. 


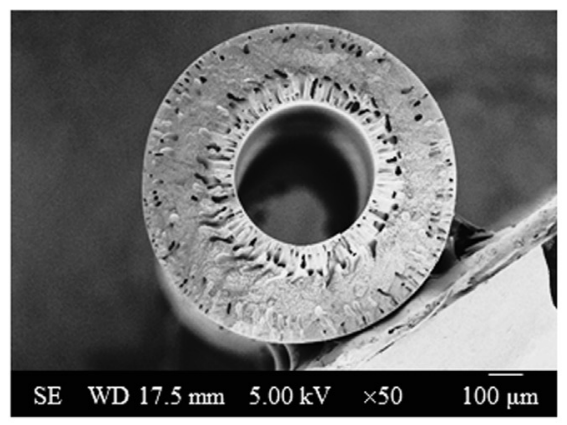

Cross section $\times 50$

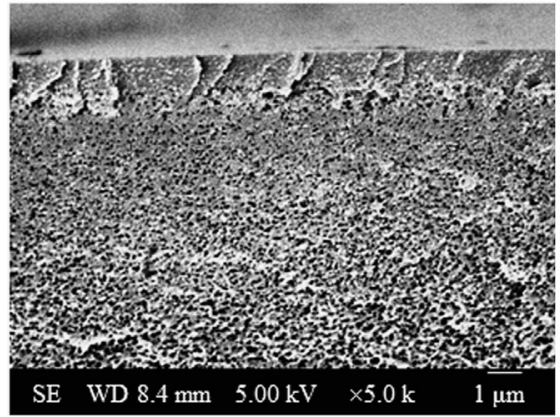

Outer edge of outer layer

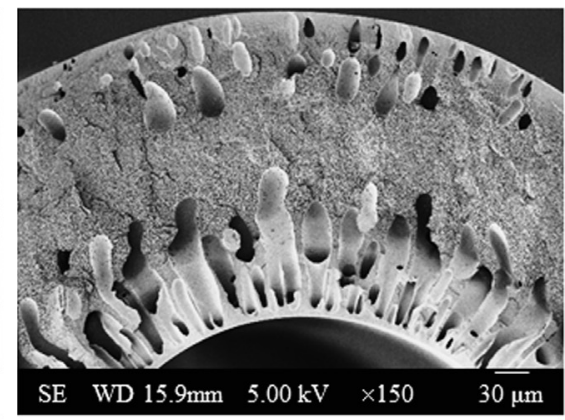

Cross section $\times 150$

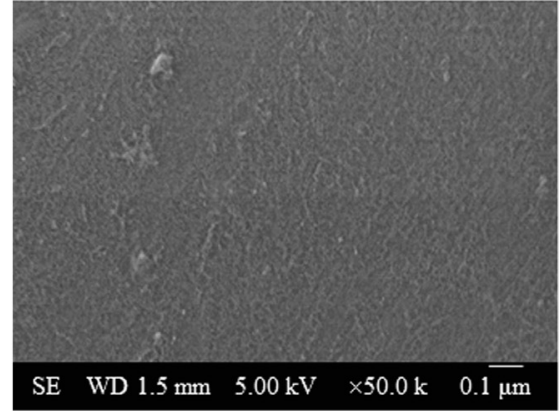

Outer surface

Fig. 4. Morphology of the PMIA nanofiltration hollow fiber membrane.

\subsection{Water flux and charge characterization of PMIA NF hollow fiber} membrane

Fig. 5(A) shows the permeation performance of the PMIA hollow fiber membrane under different trans-membrane pressures. It can be seen that pressure has a significant influence on the separation performance. The pure water flux $(F)$ increases almost linearly as the pressure increases from $4 \times 10^{5} \mathrm{~Pa}$ to $10 \times 10^{5} \mathrm{~Pa}$. The one week filtration test under a pressure of $10 \times 10^{5}$ Pa was carried out to verify the long term stability of the PMIA hollow fiber membrane. According to Fig. 5(B), the pure water flux decreases rapidly at the first $10 \mathrm{~h}$, and then becomes stable at the following $150 \mathrm{~h}$. The flux reduction in the first few hours is due to the compaction of the membrane surface under the high pressure and/or the pore plugging impact by fouling [42]. The SEM pictures indicate no significant deformation or shrinkage of the pores of the hollow fiber membranes before and after one week filtration test under $10 \times 10^{5} \mathrm{~Pa}$. This proves that the membrane has a very good mechanical stability that is attributed to the rigid aramid groups and the three-dimensional hydrogen bonding networks of the PMIA polymer.

The PMIA NF hollow fiber membranes exhibit different rejections to cations and anions owing to the negatively charged surface properties of the NF membrane. Fig. 5(C) shows the rejections to four types of electrolytes at a concentration of $3.4 \mathrm{mM}, \mathrm{pH}=7$, and different pressures. The salt rejection $(R)$ decreases in an order of $R\left(\mathrm{Na}_{2} \mathrm{SO}_{4}\right)>R\left(\mathrm{MgSO}_{4}\right)>R(\mathrm{NaCl})>R\left(\mathrm{MgCl}_{2}\right)$. The PMIA NF membrane displays higher rejections to salts containing divalent anions with a higher co-ion charge, and lower rejections to salts containing divalent cations with a higher counter-ion charge. This observation is consistent with the exclusion mechanism, as reported by Donnan [43]. That is, the sulfonic acid groups on the membrane surface exert a stronger electrostatic repulsion effect on $\mathrm{SO}_{4}^{2-}$ than on $\mathrm{Cl}^{-}$. According to the Donnan exclusion mechanism, the extent of rejection of these 1:1 type electrolytes $\left(\mathrm{MgSO}_{4}\right.$ and $\left.\mathrm{NaCl}\right)$ shall be equal; however, a lower rejection level of $\mathrm{NaCl}$ relative to that of $\mathrm{MgSO}_{4}$ is observed in this study. This phenomenon is attributed to the higher diffusivities of the smaller-sized hydrated $\mathrm{Na}^{+}$and $\mathrm{Cl}^{-}$when compared with those of the larger hydrated $\mathrm{Mg}^{2+}$ and $\mathrm{SO}_{4}^{2-}[44,45]\left(\mathrm{Na}^{+}\right.$is bigger than $\mathrm{Mg}^{2+}$ ). Additionally, it can be observed that the rejection of $\mathrm{NaCl}$ is higher than that of $\mathrm{MgCl}_{2}$. This can be explained by the charge shielding effect: $\mathrm{Mg}^{2+}$ has a higher positive charge density than $\mathrm{Na}^{+}$ that enhances the shielding effect of the NF membrane negative charge, leading to a reduced rejection degree of $\mathrm{Mg}^{2+}$. The solute rejections of all four studied electrolytes increase with increasing applied trans-membrane pressures. This is due to the fact that the water flux increases relatively higher than the solute flux, which causes a decrease in solute permeate concentration and an increase in solute rejection.

\subsection{Characterization of membrane molecular weight cut-off, mean effective pore size, and pore size distribution}

The PMIA NF hollow fiber membranes are characterized by the solute transport method to determine the molecular weight cutoff (MWCO, molecular weight of solute with a retention level of $90 \%$, mean effective pore size, and pore size distribution of the membrane. The relationship between the neutral solute Stokes radius and solute rejection is illustrated in Fig. 6(A). The MWCO of PMIA NF hollow fiber membrane is $904 \mathrm{Da}$, as calculated from Eq. (5). The cumulative pore size distribution curve and probability density function curve of PMIA NF hollow fiber membrane, as determined by Eqs. (3) and (4), respectively, are illustrated in Fig. 6 (B) and (C), respectively. The PMIA membranes exhibit a narrow pore size distribution with a mean effective pore radius of $0.404 \mathrm{~nm}$. These results indicate that the PMIA NF membrane has the potential to effectively remove PFOS molecule that has a molecular size of $1.088 \mathrm{~nm}$.

\subsection{Effect of PFOS concentration on PFOS rejection}

The effect of PFOS concentration (i.e., 50, 100, 200, and $500 \mu \mathrm{g} / \mathrm{L}$ ) on the rejection of PFOS using the PMIA NF hollow fiber membrane is studied, and the experimental results are shown in Fig. 7(A) and (B). As observed, (1) PFOS rejection increases with increasing PFOS 
A

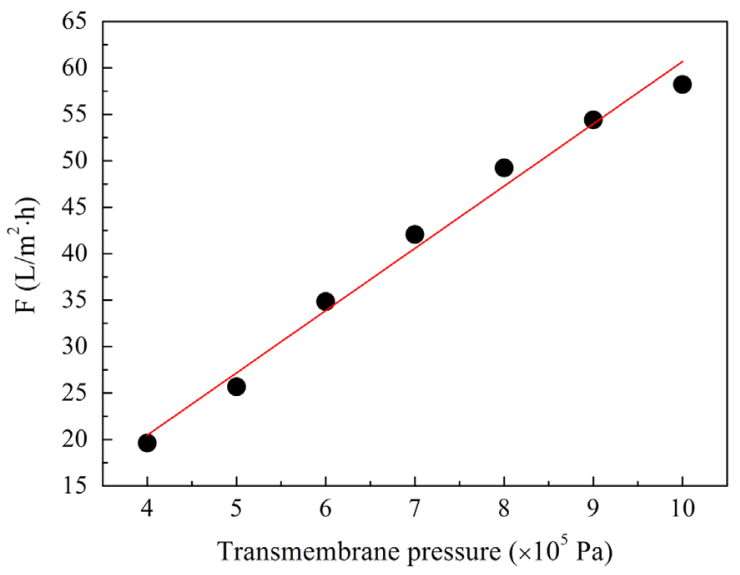

B

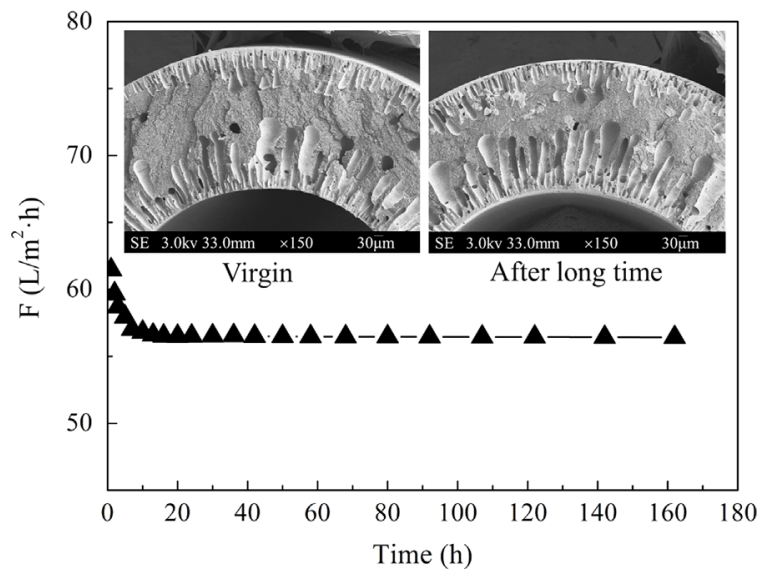

C

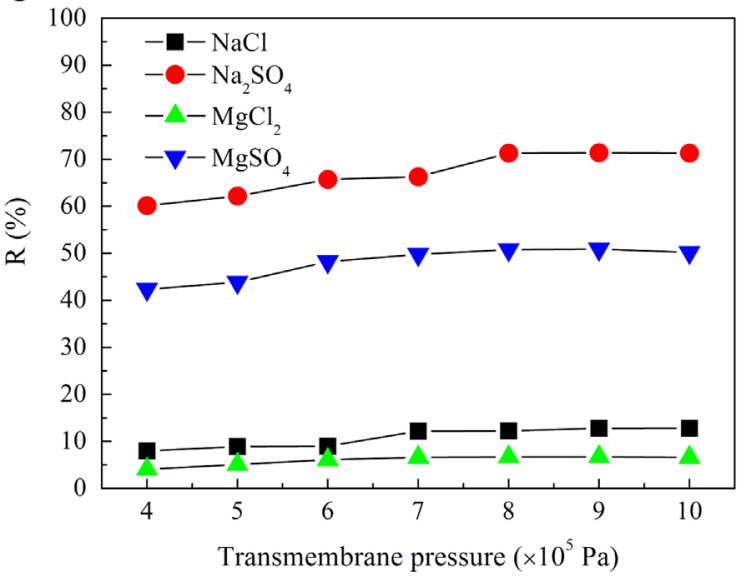

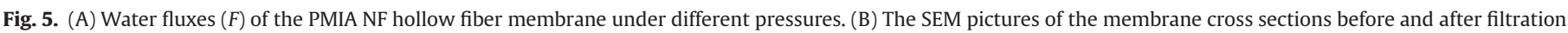
test and the change of the water flux in one week test under $10 \times 10^{5} \mathrm{~Pa}$. (C) Rejections to different salts at different pressures.

concentrations at all trans-membrane pressures; (2) the water fluxes gradually decrease at the first $700 \mathrm{~min}$ then become stable; and (3) the water fluxes increase with the decrease in the PFOS concentration. Similar results were also observed by Tang et al. [16] who attributed these to the increased amount of PFOS molecules entrapped in the pores and accumulating on the membrane surface that caused the lower water flux and higher PFOS rejection. The separation mechanisms of the NF membranes follow (1) size exclusion and (2) electrostatic effect. Typically, the size exclusion mechanism dominates the overall separation performance. Thus, as the concentration of the PFOS and the operation time increase, the amount of PFOS molecules entrapped in the PMIA polyamide skin and accumulating on the membrane surface shall also increase. This leads to the reduction in water flux and augment in PFOS rejection.

Interestingly, the rejection level of PFOS decreases with increasing pressures from $4 \times 10^{5}$ to $10 \times 10^{5} \mathrm{~Pa}$ at a given PFOS concentration. The MW of PFOS is $538 \mathrm{Da}$, which is lower than MWCO of PMIA membrane. Thus, the dominating mechanism of controlling PFOS rejection stems from the repulsion between membrane and PFOS molecule not the size exclusion. Hence, the main factors of influencing PFOS rejection are the PFOS characteristic parameters. Another important factor is the concentration polarization. Concentration polarization is severe at a high transmembrane pressure and can cause a decrease in PFOS rejection. Although the increased convective transport can influence the retention of PFOS, the contribution of the increased concentration polarization to the reduction in PFOS retention is the dominant factor [46].

\subsection{Effect of solution $\mathrm{pH}$ on $\mathrm{PFOS}$ rejection}

The separation performance of the PMIA NF hollow fiber membrane mainly depends on the membrane surface charge, which can be influenced by the solution $\mathrm{pH}$. The PMIA membrane is believed to be positively charged at low pHs and negatively charged at high $\mathrm{pHs}$. Therefore, the rejection of PFOS is likely to vary according to the solution pH. Fig. 8(A) shows the effect of solution $\mathrm{pH}$ on the removal of PFOS. As observed, the solution $\mathrm{pH}$ has a significant influence on the PFOS rejection. The rejection to PFOS improves from $91.17 \%$ to $97.49 \%$ as solution $\mathrm{pH}$ increases from 3.2 to 9.5 at $4 \times 10^{5} \mathrm{~Pa}$. PFOS has a pKa of about -4 [47], hence under the studied $\mathrm{pH}$, PFOS exists as anions in solution; the removal of PFOS at different pHs is affected by the properties of the membrane surface [48]. Fig. 8(B) shows the zeta potentials of the PMIA NF hollow fiber membrane at different pHs. The membrane displays increasing surface charge with increasing $\mathrm{pH}$. This is due to that the polyamide membrane skin layer possesses dissociable carboxylic group. Thus, the membrane surface can exhibit either a negative or a positive surface charge depending on the solution $\mathrm{pH}$ [49]. The zeta potential measurements support this conclusion since the NF membrane has much stronger negative charge at alkaline conditions than positive charge at acid conditions [50]. Because the point of zero charge of the PMIA membrane is $\sim 3.54$, the membrane surface is negative when $\mathrm{pH}$ is greater than 3.54. Accordingly, rejection of PFOS is lower at $\mathrm{pH}=3.2$ and higher as $\mathrm{pH}>3.2$. The higher rejection is attributed to the stronger electrostatic repulsion between the PFOS and PMIA membrane surface with increasing $\mathrm{pH}$. 

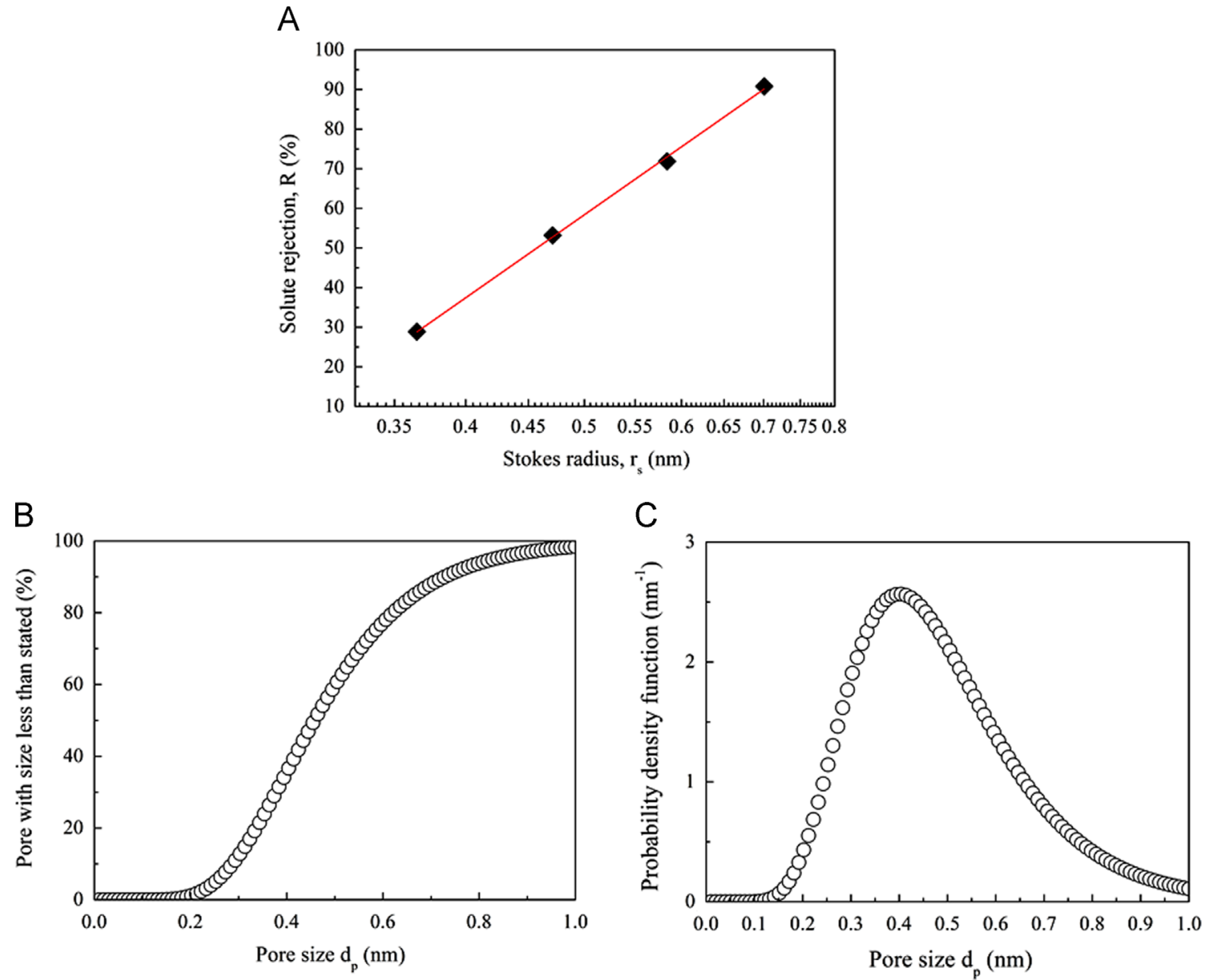

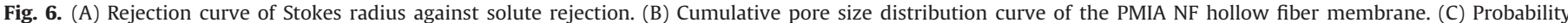
density function curve of the PMIA NF hollow fiber membrane.

A

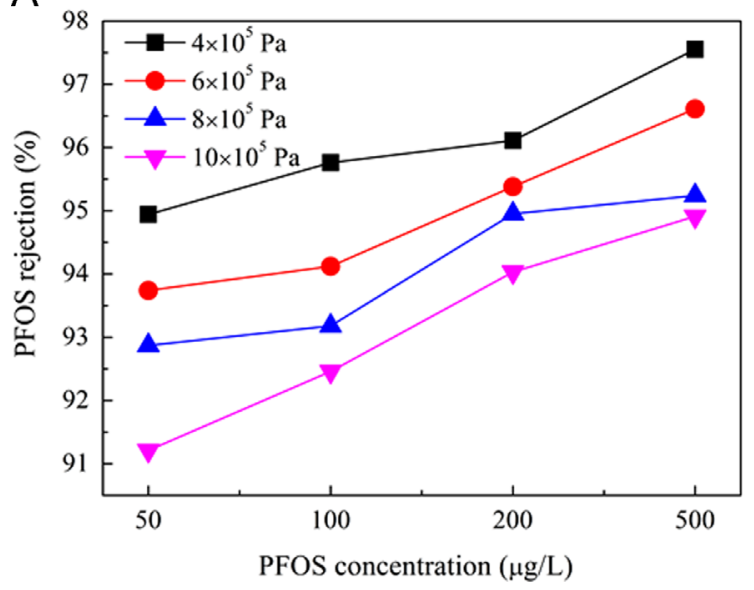

B

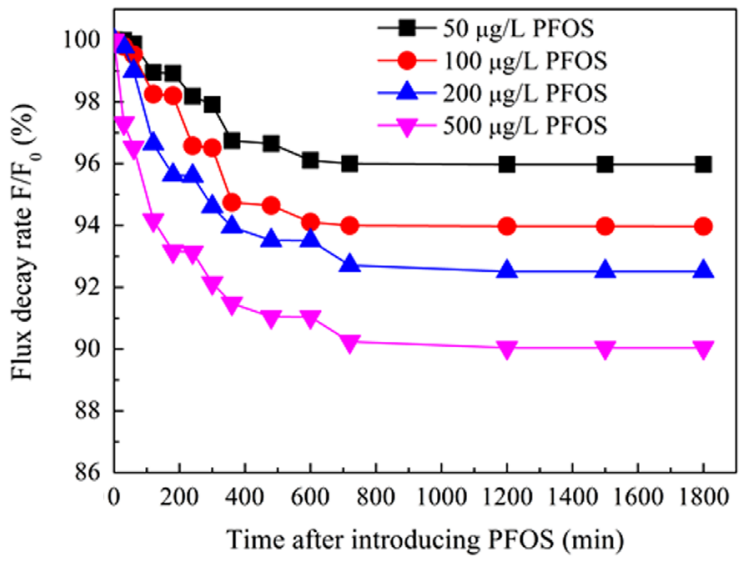

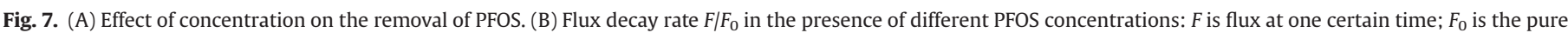
water flux.

\subsection{Effect of ionic strength on PFOS rejection}

To study the effect of ionic strength on PFOS rejection, calcium chloride $\left(\mathrm{CaCl}_{2}\right)$ which is typically present in water is used as the background electrolyte calcium ions. Calcium ions at a concentration of $\sim 2 \mathrm{mM}$ have been detected in natural water sources [51]. Therefore, in this study, calcium ions at concentrations from $0.1 \mathrm{mM}$ to $2 \mathrm{mM}$ are added to the feed solution containing $100 \mu \mathrm{g} / \mathrm{L}$ PFOS at
$\mathrm{pH}=7$ to investigate the effect of ionic strength on PFOS rejection. As shown in Fig. 9(A), the rejections of PFOS increase with increasing $\mathrm{Ca}^{2+}$ concentrations at a given trans-membrane pressure. An increase in PFOS rejection from $97.10 \%$ to $99.40 \%$ at $4 \times 10^{5} \mathrm{~Pa}$ is observed when the $\mathrm{Ca}^{2+}$ concentrations increase from $0.1 \mathrm{mM}$ to $2 \mathrm{mM}$. The improvement can be attributed to pore blockage effects as exerted by the ions [52,53]. Accordingly, the effective pore size on the membrane surface is expected to decrease, and consequently leads to increased 
A

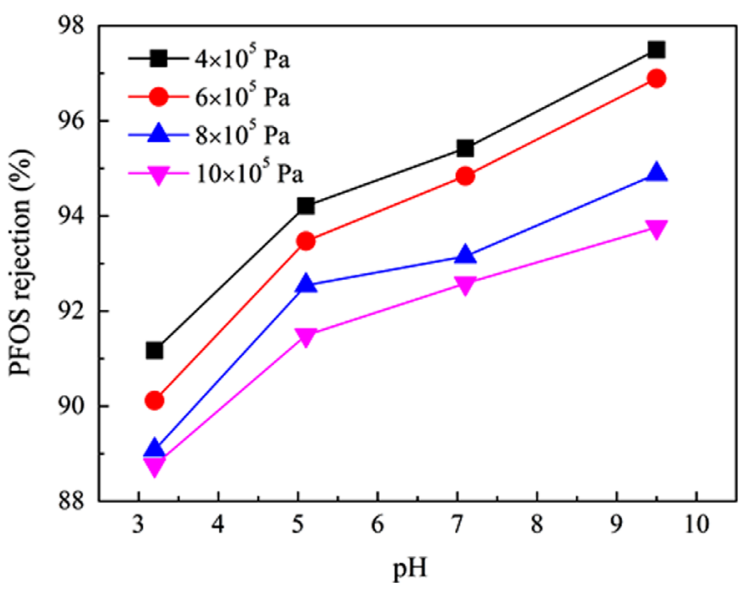

B

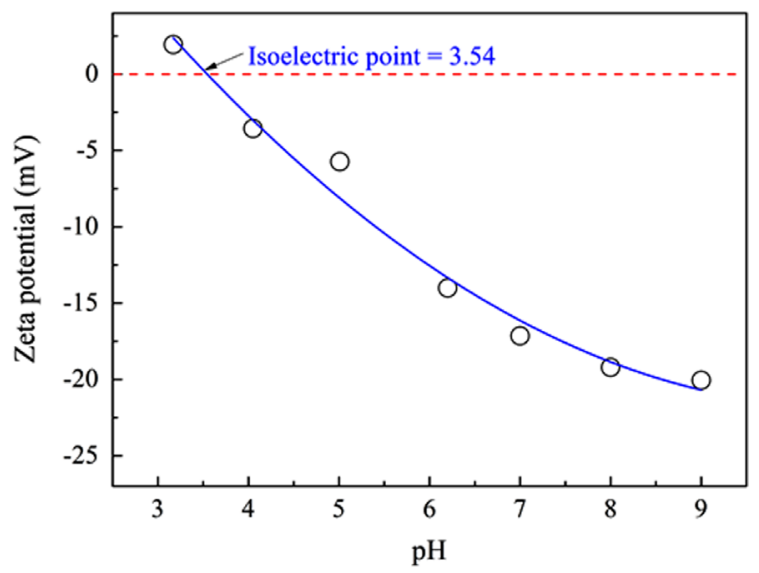

Fig. 8. (A) Effect of solution pH on the removal of PFOS. (B) Zeta potentials of the PMIA NF membrane at different solution pHs.

A

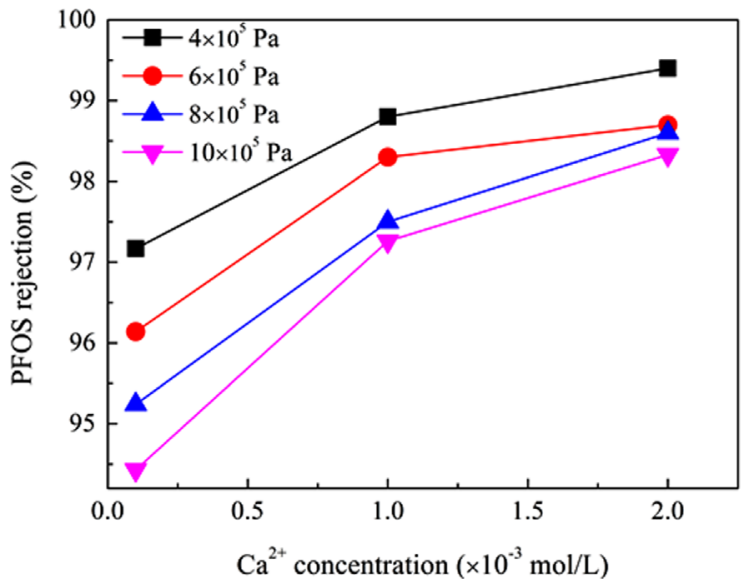

B

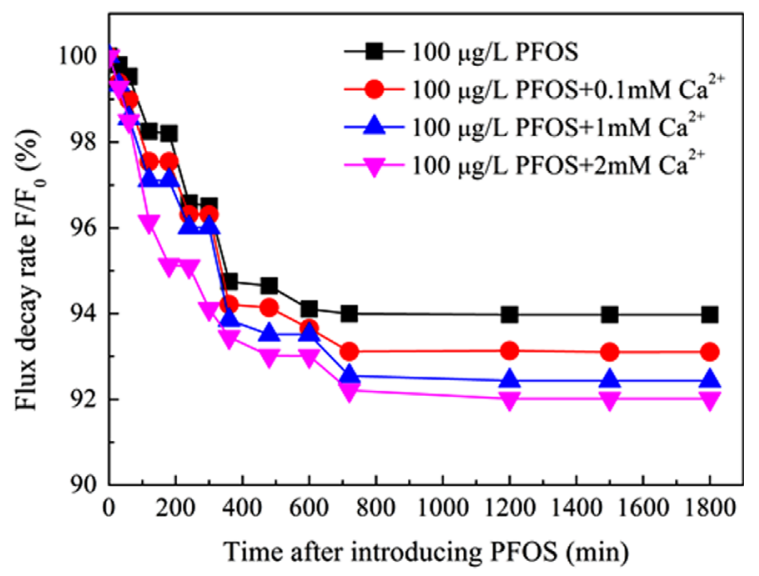

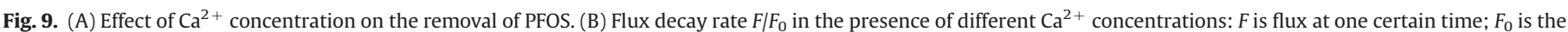
pure water flux.

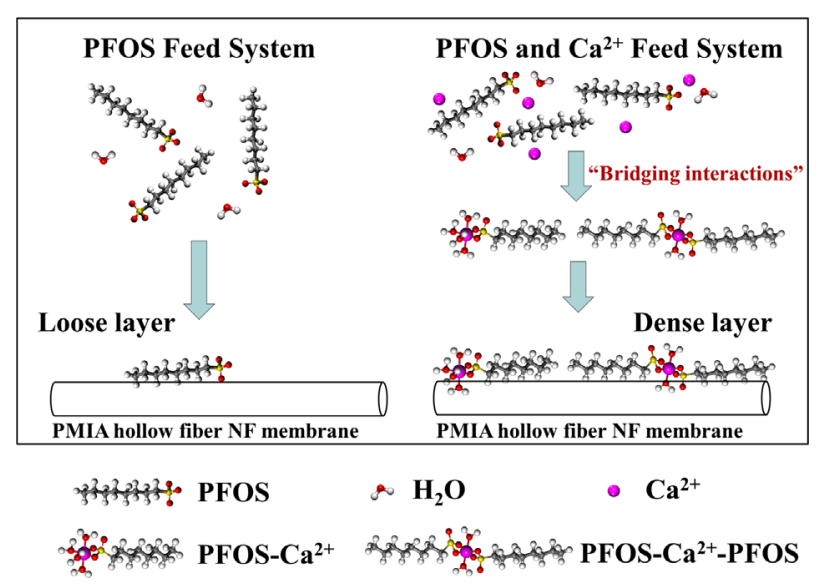

Fig. 10. The schematic diagram for different PFOS systems.

rejection of PFOS. Membrane pore blockage by $\mathrm{Ca}^{2+}$ will lower the number of available pores for filtration. This will hinder the passage of PFOS and water molecules through the membrane. As illustrated in Fig. 9(B), the presence of $\mathrm{Ca}^{2+}$ in the feed solution leads to a reduction in permeate flux compared with that in the absence of $\mathrm{Ca}^{2+}$, with slightly higher flux decay rates with increasing $\mathrm{Ca}^{2+}$ concentrations. Thus, the comparison of the flux decay rate suggests

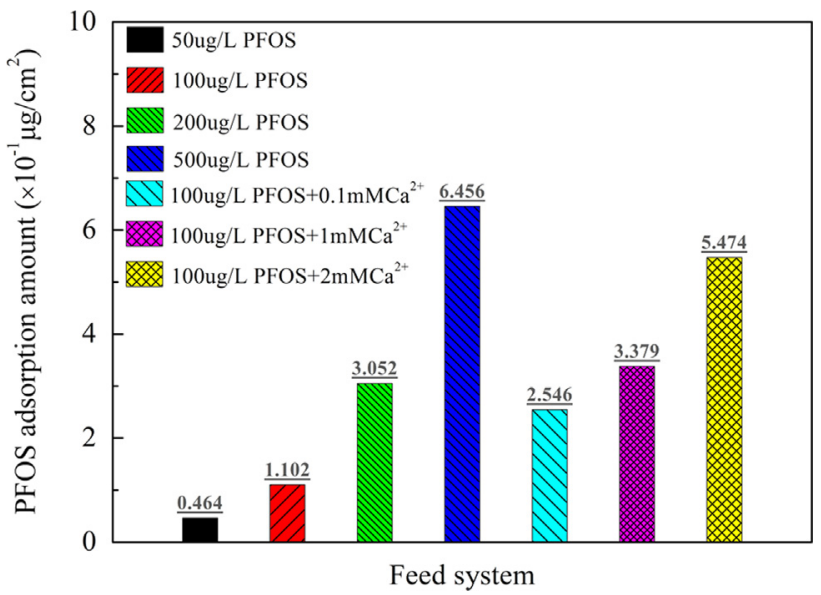

Fig. 11. Adsorption amount of PFOS in different feed solutions.

that a higher $\mathrm{Ca}^{2+}$ concentrations results in the increased $\mathrm{Ca}^{2+}$ precipitation on the membrane and pore blockage, consequently leading to increased PFOS rejection and flux decline [54-56].

Moreover, some researchers attribute this beneficial effect to the onset of specific bridging interactions between $\mathrm{Ca}^{2+}$ and the sulfonate group of PFOS [57-59]. Zhao et al. further demonstrate the formation of $\mathrm{CF}_{3}\left(\mathrm{CF}_{2}\right)_{7} \mathrm{SO}_{3} \mathrm{Ca}^{2+}$ cation and neutral $\mathrm{CF}_{3}\left(\mathrm{CF}_{2}\right)_{7} \mathrm{SO}_{3} \mathrm{CaO}_{3}-\mathrm{S}\left(\mathrm{CF}_{2}\right)_{7} \mathrm{CF}_{3}$ 
in this circumstance using density functional theory calculations [17]. As shown in Fig. 10, not only this bridging interaction improves molecular polarity, but also increases the molecule size of PFOS.
$\mathrm{Ca}^{2+}$ as a cation enhances the adsorption of negatively charged PFOS and further creates a dense layer on the membrane surface. Accordingly, the membrane sieve effect is expected to be more effective
A
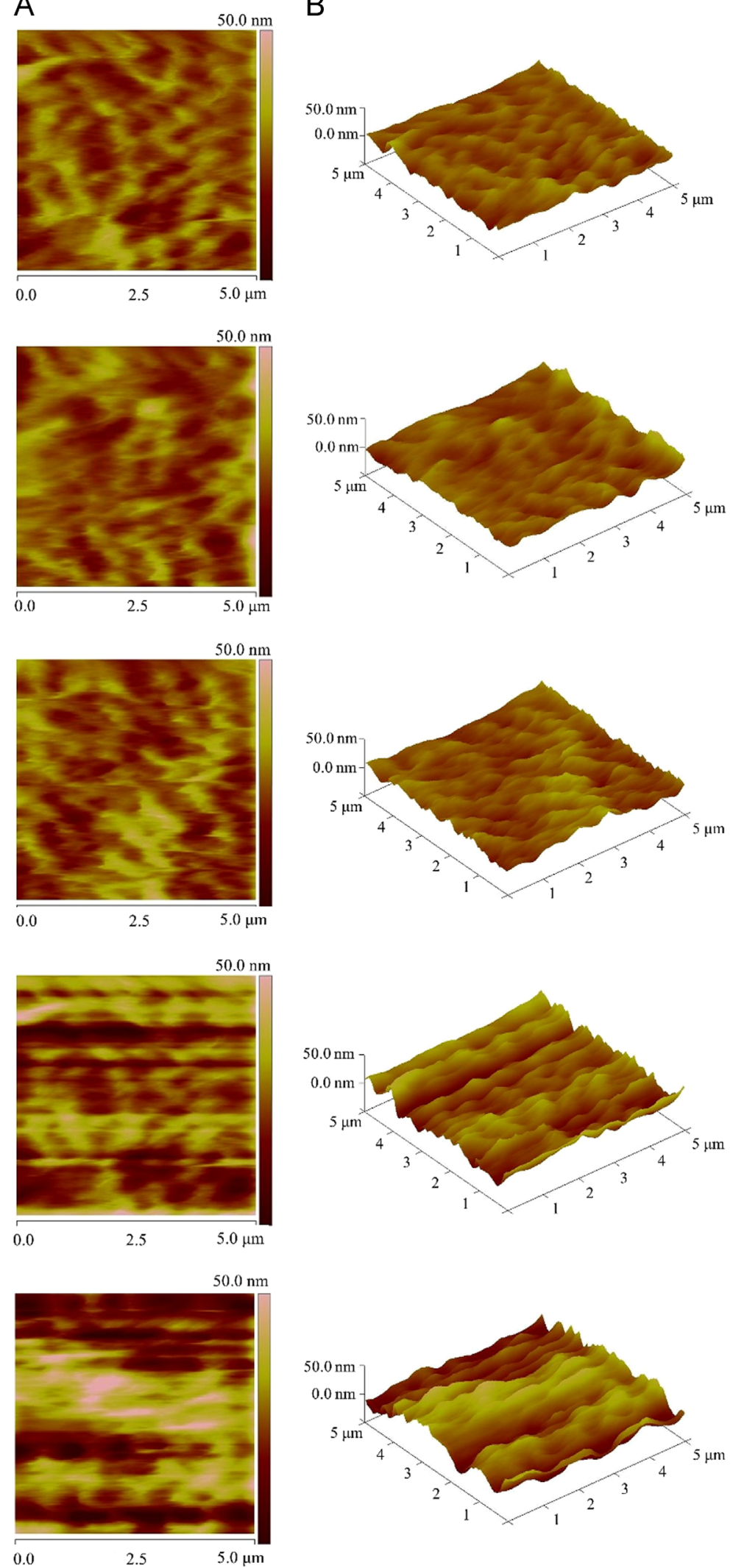

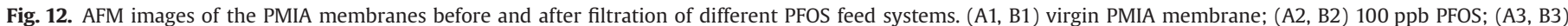
$100 \mathrm{ppb}$ PFOS $+0.1 \mathrm{mM} \mathrm{Ca}^{2+}$; (A4, B4) $100 \mathrm{ppb}$ PFOS $+1 \mathrm{mM} \mathrm{Ca}^{2+}$; and (A5, B5) $100 \mathrm{ppb}$ PFOS $+2 \mathrm{mM} \mathrm{Ca}^{2+}$. 
Table 3

Roughness parameters of the virgin PMIA membrane and PFOS accumulation on the PMIA membrane surface with different experimental systems.

\begin{tabular}{lcll}
\hline Feed system & $R_{\mathrm{q}}(\mathrm{nm})$ & $R_{\mathrm{a}}(\mathrm{nm})$ & $R_{\max }(\mathrm{nm})$ \\
\hline Virgin PMIA membrane & 4.64 & 3.67 & 34.3 \\
100 ppb PFOS & 4.94 & 3.83 & 44.2 \\
100 ppb PFOS $+0.1 \mathrm{mM} \mathrm{Ca}^{2+}$ & 5.42 & 4.38 & 48.3 \\
100 ppb PFOS $+1 \mathrm{mM} \mathrm{Ca}^{2+}$ & 8.85 & 6.92 & 65.0 \\
100 ppb PFOS $+2 \mathrm{mM} \mathrm{Ca}^{2+}$ & 11.9 & 9.79 & 68.6 \\
\hline
\end{tabular}

under these conditions. It can thus be concluded that the PFOS rejection can be improved in the presence of $\mathrm{Ca}^{2+}$ ions, owing to interactions with the membrane and PFOS molecules.

\subsection{Desorption of PFOS}

Perfluorooctanesulfonic acid (PFOS) filtration tests using the home-made PMIA hollow fiber nanofiltration membranes were carried out and the rejection to PFOS was higher than 94\%. In addition, the rejection of PFOS could be further improved by adjusting the $\mathrm{pH}$ value or adding $\mathrm{Ca}^{2+}$ cation into the PFOS solutions. However, a decrease in the water flux with the operation time was observed that was attributed to the accumulation of PFOS on the membrane surface. To investigate this phenomenon, the PFOS adsorption on the PMIA hollow fiber membrane was determined using a method similar to Ref. [60] Furthermore, atomic force microscopy (AFM) was also adopted to characterize the three-dimensional image and roughness of the surface of the virgin and fouled membrane [61-65]. Flux reduction as observed from Figs. 7(B) and 9(B)suggests that there is certain amount of PFOS adsorbing to the PMIA NF membrane. Fig. 11 presents the adsorption amount of PFOS in different feed solutions. The sorption amount of PFOS increases from $0.464 \times 10^{-1}$ to $6.456 \times 10^{-1} \mu \mathrm{g} / \mathrm{cm}^{2}$ when the PFOS concentration increases from 50 to $500 \mu \mathrm{g} / \mathrm{L}$. The higher sorption amounts of PFOS at the higher PFOS concentrations indicate a higher number of PFOS molecules accumulating on the membrane surface or entrapped in the membrane pores. The addition of $\mathrm{Ca}^{2+}$ ions also enhances the sorption capacities. The PFOS adsorbing on the membrane surface is $5.474 \times 10^{-1} \mu \mathrm{g} / \mathrm{cm}^{2}$ at a concentration of $2 \mathrm{mM} \mathrm{Ca}^{2+}$, which is approximate five times higher than without $\mathrm{Ca}^{2+}$. AFM images shown in Fig. 12 also prove these results. The PFOS adhesion has a strong influence on surface roughness. As shown in Table 3, the virgin PMIA membrane has an average roughness of $3.67 \mathrm{~nm}$, and the average roughness increases from $3.83 \mathrm{~nm}$ to $9.79 \mathrm{~nm}$ with increasing $\mathrm{Ca}^{2+}$ concentration. Clearly, more $\mathrm{Ca}^{2+}$ facilitates PFOS adsorption on the membrane surface and increases surface roughness. The significant improvement in the sorption capacity can be attributed to the neutralization of the negatively charged PFOS and PMIA NF membrane surface by $\mathrm{Ca}^{2+}$. The sorption and entrapment of PFOS on the membrane greatly inhibit the passage of water molecules. Therefore, the water flux decreases and the PFOS rejection is improved by adding $\mathrm{Ca}^{2+}$.

\section{Conclusion}

A novel negatively charged PMIA nanofiltration hollow fiber membrane with high-pressure resistant has been fabricated by a dry-wet phase inversion technique. The membrane possesses a typical asymmetric structure. The MWCO and mean effective pore size of the membrane are $904 \mathrm{Da}$ and $0.404 \mathrm{~nm}$, respectively. The PMIA NF membrane rejects different salts in the order of $\mathrm{Na}_{2} \mathrm{SO}_{4}>\mathrm{MgSO}_{4}>$ $\mathrm{NaCl}>\mathrm{MgCl}_{2}$ at $\mathrm{pH}$ 7.0. The rejection level of salts containing divalent anions is higher than that of salts containing divalent cations, in accordance with the Donnan effect. The PMIA NF hollow fiber membrane efficiently rejects PFOS owing to a combined steric hindrance and Donnan exclusion effect. Filtration experiments indicate that the rejection of PFOS increases with increasing PFOS concentration and solution $\mathrm{pH}$. Rejection of PFOS increases from 91.17\% to $97.49 \%$ as $\mathrm{pH}$ increases from 3.2 to 9.5 at a pressure of $4 \times 10^{5} \mathrm{~Pa}$. Moreover, a higher $\mathrm{Ca}^{2+}$ concentration improves the PFOS rejection owing to pore blockage and specific bridging interactions between $\mathrm{Ca}^{2+}$ and the sulfonate group of PFOS. These factors not only improve molecular polarity, but also increase the molecule size of PFOS. Desorption experiments show that the sorption amount of PFOS increases with increasing PFOS concentration or ionic strength. AFM images also demonstrate that the membrane surface roughness increases with the increasing $\mathrm{Ca}^{2+}$ concentration. Overall, these results suggest that the newly fabricated PMIA NF hollow fiber membranes have potential for application in PFOS removal.

\section{Acknowledgments}

This work was financially supported by the National Natural Science Foundation of China (Nos. 21176245 and 50978245), the National Science and Technology Support Program of China (Nos. 2012BAJ25B02 and 2012BAJ25B06) and the special fund of State Key Joint Laboratory of Environment Simulation and Pollution Control (No. 12L02ESPC).

\section{Nomenclature}

PMIA poly( $m$-phenylene isophthalamide)

PFOS perfluorooctane sulfonate

POPs persistent organic pollutants

$\mathrm{NaCl}$ sodium chloride

$\mathrm{Na}_{2} \mathrm{SO}_{4}$ sodium sulfate

$\mathrm{MgCl}_{2}$ magnesium chloride

$\mathrm{MgSO}_{4}$ magnesium sulfate

$\mathrm{CaCl}_{2} \quad$ calcium chloride

DMAC $\quad N, N$-dimethylacetamide

PVP K15 poly vinylpyrrolidone K15

$\mathrm{LiCl} \quad$ lithium chloride

$F \quad$ water flux $\left(\mathrm{L} / \mathrm{m}^{2} \mathrm{~h}\right)$

$J \quad$ water permeation volume (L)

$S \quad$ membrane effective filtration area $\left(\mathrm{m}^{2}\right)$

$t \quad$ operation time (h)

$R \quad$ rejection (\%)

$C_{\mathrm{p}} \quad$ permeate concentrations $(\mathrm{g} / \mathrm{L})$

$C_{\mathrm{o}} \quad$ feed concentrations $(\mathrm{g} / \mathrm{L})$

MWCO molecular weight cut-off (Da)

$R_{\mathrm{T}} \quad$ solute rejection (\%)

$r_{\mathrm{s}} \quad$ Solute radius $(\mathrm{nm})$

$\mu_{\mathrm{s}} \quad$ geometric mean radius (nm)

$\sigma_{\mathrm{g}} \quad$ geometric standard deviation

$\mu_{\mathrm{p}} \quad$ mean effective pore radius (nm)

$\sigma_{\mathrm{p}} \quad$ geometric standard deviation

$d_{\mathrm{p}} \quad$ effective pore radius $(\mathrm{nm})$

MW molecular weight $(\mathrm{g} / \mathrm{mol})$

\section{References}

[1] E. Kissa, Fluorinated Surfactants: Synthesis, Properties, and Applications, Marcel Dekker, New York, 1994.

[2] S. Fujii, C. Polprasert, S. Tanaka, N.P.H. Lien, Y. Oiu, New POPs in the water environment: distribution, bioaccumulation and treatment of perfluorinated 
compounds - a review paper, J. Water Supply: Res. Technol. - Aqua 56 (2007) 313-326.

[3] J.P. Giesy, K. Kannan, Global distribution of perfluorooctane sulfonate in wildlife, Environ. Sci. Technol. 35 (2001) 1339-1342.

[4] J.P. Giesy, K. Kannan, Peer reviewed: perfluorochemical surfactants in the environment, Environ. Sci. Technol. 36 (2002) 146A-152A.

[5] C.Y. Tang, Q.S. Fu, C.S. Criddle, J.O. Leckie, Effect of flux (transmembrane pressure) and membrane properties on fouling and rejection of reverse osmosis and nanofiltration membranes treating perfluorooctane sulfonate containing wastewater, Environ. Sci. Technol. 41 (2007) 2008-2014.

[6] J.L. Newsted, P.D. Jones, K. Coady, J.P. Giesy, Avian toxicity reference values for perfluorooctane sulfonate, Environ. Sci. Technol. 39 (2005) 9357-9362.

[7] T. Wang, Y. Wang, C. Liao, Y. Cai, G. Jiang, Perspectives on theinclusion of perfluorooctane sulfonate into the Stockholm Convention on Persistent Organic Pollutants, Environ. Sci. Technol. 43 (2009) 5171-5175.

[8] S. Deng, Q. Zhou, G. Yu, J. Huang, Q. Fan, Removal of perfluorooctanoate from surface water by polyaluminium chloride coagulation, Water Res. 45 (2011) 1774-1780.

[9] M. Wilhelm, S. Bergmann, H.H. Dieter, Occurrence of perfluorinated compounds (PFCs) in drinking water of North Rhine-Westphalia, Germany and new approach to assess drinking water contamination by shorter-chained C4-C7 PFCs, Int. J. Hyg. Environ. Health 213 (2010) 224-232.

[10] H.F. Schroder, R.J.W. Meesters, Stability of fluorinated surfactants in advanced oxidation processes - a follow up of degradation products using flow injection-mass spectrometry, liquid chromatography-mass spectrometry and liquid chromatography-multiple stage mass spectrometry, J. Chromatogr. A 1082 (2005) 110-119.

[11] C.D. Vecitis, H. Park, J. Cheng, B.T. Mader, M.R. Hoffmann, Treatment technologies for aqueous perfluorooctanesulfonate (PFOS) and perfluorooctanoate (PFOA), Front. Environ. Sci. Eng. China 3 (2009) 129-151.

[12] H. Moriwaki, Y. Takagi, M. Tanaka, K. Tsuruho, K. Okitsu, Y. Maeda, Sonochemical decomposition of perfluorooctane sulfonate and perfluorooctanoic acid, Environ. Sci. Technol. 39 (2005) 3388-3392.

[13] Y. Tan, J.E. Kilduff, Factors affecting selectivity during dissolved organic matter removal by anion-exchange resins, Water Res. 41 (2007) 4211-4221.

[14] Q. Yu, R. Zhang, S. Deng, J. Huang, G. Yu, Sorption of perfluorooctane sulfonate and perfluorooctanoate on activated carbons and resin: kinetic and isotherm study, Water Res. 43 (2009) 1150-1158.

[15] T. Yamamoto, Y. Noma, S.I. Sakai, Y. Shibata, Photodegradation of perfluorooctane sulfonate by UV irradiation in water and alkaline 2-propanol, Environ. Sci. Technol. 41 (2007) 5660-5665.

[16] C.Y. Tang, Q.S. Fu, A.P. Robertson, C.S. Criddle, J.O. Leckie, Use of reverse osmosis membranes to remove perfluorooctane sulfonate (PFOS) from semiconductor wastewater, Environ. Sci. Technol. 40 (2006) 7343-7349.

[17] C. Zhao, J. Zhang, G. He, T. Wang, D. Hou, Z. Luan, Perfluorooctane sulfonate removal by nanofiltration membrane the role of calcium ions, Chem. Eng. J. 233 (2013) 224-232.

[18] R.J. Petersen, Composite reverse osmosis and nanofiltration membranes, J. Membr. Sci. 83 (1993) 81-150.

[19] R.W. Baker, Membrane Technology and Applications, second ed., John Wiley \& Sons Ltd., The Atrium, Southern Gate, Chichester, 2004.

[20] J. Ji, M. Mehta, Mathematical model for the formation of thin-film composite hollow fiber and tubular membranes by interfacial polymerization, J. Membr. Sci. 192 (2001) 41-54.

[21] W. Fang, L. Shi, R. Wang, Interfacially polymerized composite nanofiltration hollow fiber membranes for low-pressure water softening, J. Membr. Sci. 430 (2013) 129-139.

[22] H. Futselaar, H. Schonewille, W.v.d. Meer, Direct capillary nanofiltration-a new high-grade purification concept, Desalination 145 (2002) 75-80.

[23] S.K. Maurya, K. Parashuram, P.S. Singh, P. Ray, A.V.R. Reddy, Preparation of polysulfone-polyamide thin film composite hollow fiber nanofiltration membranes and their performance in the treatment of aqueous dye solutions, Desalination 304 (2012) 11-19.

[24] X.-l. Wang, J.-f. Wei, Z. Dai, K.-y. Zhao, H. Zhang, Preparation and characterization of negatively charged hollow fiber nanofiltration membrane by plasma-induced graft polymerization, Desalination 286 (2012) 138-144.

[25] Y. Yang, X. Jian, D. Yang, S. Zhang, L. Zou, Poly(phthalazinone ether sulfone ketone) (PPESK) hollow fiber asymmetric nanofiltration membranes: preparation, morphologies and properties, J. Membr. Sci. 270 (2006) 1-12.

[26] S.P. Sun, K.Y. Wang, N. Peng, T.A. Hatton, T.S. Chung, Novel polyamide-imide/ cellulose acetate dual-layer hollow fiber membranes for nanofiltration, J. Membr. Sci. 363 (2010) 232-242.

[27] S. Yu, Y. Zheng, Q. Zhou, S. Shuai, Z. Lü, C. Gao, Facile modification of polypropylene hollow fiber microfiltration membranes for nanofiltration, Desalination 298 (2012) 49-58.

[28] S. Yu, Q. Cheng, C. Huang, J. Liu, X. Peng, M. Liu, C. Gao, Cellulose acetate hollow fiber nanofiltration membrane with improved permselectivity prepared through hydrolysis followed by carboxymethylation, J. Membr. Sci. 434 (2013) 44-54.

[29] S. Yu, Z. Chen, Q. Cheng, Z. Lü, M. Liu, C. Gao, Application of thin-film composite hollow fiber membrane to submerged nanofiltration of anionic dye aqueous solutions, Sep. Purif. Technol. 88 (2012) 121-129.

[30] P. Nimmanpipug, K. Tashiro, O. Rangsiman, Factors governing the threedimensional hydrogen-bond network structure of poly(m-phenylene isophthalamide) and a series of its model compounds (4): similarity in local conformation and packing structure between a complicated three-arm model compound and the linear model compounds, J. Phys. Chem. B 110 (2006) 20858-20864.

[31] H. Kakida, Y. Chatani, H. Tadokoro, Crystal structure of poly(m-phenylene isophthalamide), J. Polym. Sci.: Polym. Phy. Ed. 14 (1976) 427-435.

[32] X.L. Wang, T. Tsuru, S. Nakao, S. Kimura, The electrostatic and steric-hindrance model for the transport of charged solutes through nanofiltration membranes, J. Membr. Sci. 135 (1997) 19-32.

[33] A.S. Michaels, Analysis and prediction of sieving curves for ultrafiltration membranes - a universal correlation, Sep. Sci. Technol. 15 (1980) 1305-1322.

[34] S. Singh, K.C. Khulbe, T. Matsuura, P. Ramamurthy, Membrane characterization by solute transport and atomic force microscopy, J. Membr. Sci. 142 (1998) $111-127$.

[35] W.R. Bowen, A.W. Mohammad, Characterization and prediction of nanofiltration membrane performance-a general assessment, Chem. Eng. Res. Des. 76 (1998) 885-893.

[36] T.S. Chung, X.D. Hu, Effect of air-gap distance on the morphology and thermal properties of polyethersulfone hollow fibers, J. Appl. Polym. Sci. 66 (1997) 1067-1077.

[37] M. Mulder, Basic Principles of Membrane Technology, Kluwer Academic Publishers, Dordrecht, 1991.

[38] I.M. Wienk, R.M. Boom, M.A.M. Beerlage, A.M.W. Bulte, C.A. Smolders, H. Strathmann, Recent advances in the formation of phase inversion membranes made from amorphous or semi-crystalline polymers, J. Membr. Sci. 113 (1996) 361-371.

[39] R.M. Boom, I.M. Wienk, T. van den Boomgaard, C.A. Smolders, Microstructures in phase inversion membranes. Part 2. The role of a polymeric additive, J. Membr. Sci. 73 (1992) 277-292.

[40] C.A. Smolders, A.J. Reuvers, R.M. Boom, I.M. Wienk, Microstructures in phaseinversion membranes. Part 1. Formation of macrovoids, J. Membr. Sci. 73 (1992) 259-275.

[41] T.H. Young, L.W. Chen, Pore formation mechanism of membranes from phase inversion process, Desalination 103 (1995) 233-247.

[42] X. Zhao, H. Zhang, J. Wang, Filtering surface water with a polyurethane-based hollow fiber membrane: effects of operating pressure on membrane fouling, Chin. J. Chem. Eng. 22 (2014) 583-589.

[43] F.G. Donnan, Theory of membrane equilibria and membrane potentials in the presence of non-dialysing electrolytes. A contribution to physical-chemical physiology, J. Membr. Sci. 100 (1995) 45-55.

[44] K. Linde, A.S. Jonsson, Nanofiltration of salt solutions and landfill leachate, Desalination 103 (1995) 223-232.

[45] J. Schaep, B. Van der Bruggen, C. Vandecasteele, D. Wilms, Influence of ion size and charge in nanofiltration, Sep. Purif. Technol. 14 (1998) 155-162.

[46] K. Mehiguene, Y. Garba, S. Taha, N. Gondrexon, G. Dorange, Influence of operating conditions on the retention of copper and cadmium in aqueous solutions by nanofiltration: experimental results and modelling, Sep. Purif. Technol. 15 (1999) 181-187.

[47] E. Steinle-Darling, M. Reinhard, Nanofiltration for trace organic contaminant removal: structure, solution, and membrane fouling effects on the rejection of perfluorochemicals, Environ. Sci. Technol. 42 (2008) 5292-5297.

[48] D. Brooke, A. Footitt, T.A. Nwaogu, Environmental Risk Evaluation Report: Perfluorooctane Sulfonate (PFOS), UK Environment Agency, Rotherham, England, 2004.

[49] M. Mänttäri, A. Pihlajamäki, M. Nyström, Effect of pH on hydrophilicity and charge and their effect on the filtration efficiency of NF membranes at different pH, J. Membr. Sci. 280 (2006) 311-320.

[50] V. Freger, A. Pihlajamaki, Y. Shabtai, J. Gilron, Distribution of fixed charge functional groups in the polyamide composite membranes, in: Supplementary Book of Abstracts, Proceedings of the International Congress on Membranes and Membrane Processes (ICOM'02), Toulouse, France, 2002, p. 144.

[51] J. Yan, J. Li, Q. Ye, K. Li, Concentrations and exports of solutes from surface runoff in Houzhai Karst Basin, southwest China, Chem. Geol. 304 (2012) 1-9.

[52] J. Hofman, T.H.M. Noij, J.C. Schippers, Removal of pesticides and other organic micropollutants with membrane filtration, in: Proceedings of the Iwsa European Specialized Conference on Recently Identified Pollutants in Water Resources - Drinking Water Treatment in the Nineties, vol. 11, 1993, pp. 129139.

[53] Y. Zhang, B. Van der Bruggen, G.X. Chen, L. Braeken, C. Vandecasteele, Removal of pesticides by nanofiltration: effect of the water matrix, Sep. Purif. Technol. 38 (2004) 163-172.

[54] K. Listiarini, W. Chun, D.D. Sun, J.O. Leckie, Fouling mechanism and resistance analyses of systems containing sodium alginate, calcium, alum and their combination in dead-end fouling of nanofiltration membranes, J. Membr. Sci. 344 (2009) 244-251.

[55] K.V. Plakas, A.J. Karabelas, Membrane retention of herbicides from single and multi-solute media: the effect of ionic environment, J. Membr. Sci. 320 (2008) 325-334.

[56] Y.-N. Wang, C.Y. Tang, Nanofiltration membrane fouling by oppositely charged macromolecules: investigation on flux behavior, foulant mass deposition, and solute rejection, Environ. Sci. Technol. 45 (2011) 8941-8947.

[57] S. Hyun, L.S. Lee, Quantifying the contribution of different sorption mechanisms for 2,4-dichlorophenoxyacetic acid sorption by several variable-charge soils, Environ. Sci. Technol. 39 (2005) 2522-2528.

[58] G. Mezei, R.G. Raptis, Pyrazole-4-sulfonate networks of alkali and alkalineearth metals. Effect of cation size, charge, H-bonding and aromatic interactions on the three-dimensional supramolecular architecture, New J. Chem. 27 (2003) 1399-1407. 
[59] F. Wang, K.M. Shih, Adsorption of perfluorooctanesulfonate (PFOS) and perfluorooctanoate (PFOA) on alumina: influence of solution $\mathrm{pH}$ and cations, Water Res. 45 (2011) 2925-2930.

[60] Y.N. Kwon, K. Shih, C.Y. Tang, J.O. Leckie, Adsorption of perfluorinated compounds on thin-film composite polyamide membranes, J. Appl. Polym. Sci. 124 (2012) 1042-1049.

[61] C.Y. Tang, Y.N. Kwon, J.O. Leckie, The role of foulant-foulant electrostatic interaction on limiting flux for RO and NF membranes during humic acid fouling-theoretical basis, experimental evidence, and AFM interaction force measurement, J. Membr. Sci. 326 (2009) 526-532.
[62] A.R. Costa, M.N. de Pinho, M. Elimelech, Mechanisms of colloidal natural organic matter fouling in ultrafiltration, J. Membr. Sci. 281 (2006) 716-725.

[63] E.M. Vrijenhoek, S. Hong, M. Elimelech, Influence of membrane surface properties on initial rate of colloidal fouling of reverse osmosis and nanofiltration membranes, J. Membr. Sci. 188 (2001) 115-128.

[64] L.D. Tijing, Y.C. Woo, J.-S. Choi, S. Lee, S.H. Kim, H.K. Shon, Fouling and its control in membrane distillation-a review, J. Membr. Sci. 475 (2015) 215-244.

[65] W.R. Bowen, N. Hilal, R.W. Lovitt, C.J. Wright, Characterisation of membrane surfaces: direct measurement of biological adhesion using an atomic force microscope, J. Membr. Sci. 154 (1999) 205-212. 